\title{
Dynamics, Brandom-style
}

\section{Citation}

Nickel, Bernhard. 2011. “Dynamics, Brandom-Style.” Philosophical Studies 162 (2) (July 12): 333-354.

\section{Published Version}

doi:10.1007/s11098-011-9768-4

\section{Permanent link}

http://nrs.harvard.edu/urn-3:HUL.InstRepos:13041028

\section{Terms of Use}

This article was downloaded from Harvard University's DASH repository, and is made available under the terms and conditions applicable to Open Access Policy Articles, as set forth at http:// nrs.harvard.edu/urn-3:HUL.InstRepos:dash.current.terms-of-use\#OAP

\section{Share Your Story}

The Harvard community has made this article openly available.

Please share how this access benefits you. Submit a story.

Accessibility 


\title{
Dynamics, Brandom-Style*
}

\author{
Bernhard Nickel · Harvard University
}

\begin{abstract}
This paper discusses the semantic theory presented in Robert Brandom's Making It Explicit. I argue that it is best understood as a special version of dynamic semantics, so that these semantics by themselves offer an interesting theoretical alternative to more standard truth-conditional theories. This reorientation also has implications for more foundational issues. I argue that it gives us the resources for a renewed argument for the normativity of meaning. The paper ends by critically assessing the view in both its development and motivations.
\end{abstract}

Keywords STATIC SEMANTICS - DYNAMIC SEMANTICS · INCOMPATIBILITY SEMANTICS $\cdot$ BRANDOM $\cdot$ NORMS $\cdot$ ANAPHORA

*The material for this paper grew out of a seminar I taught at Harvard University in the Spring of 2008. I want to thank the participants in that seminar for lots of helpful discussion, especially Ephraim Glick, Jon Litland, Paul Pietroski, and James Shaw. 


\section{Introduction}

Truth is the basic concept in many semantic theories for natural language. They assign truth-conditions or truth-values to sentences and semantic values to subsentential expressions that account for their contribution to the determination of the truth-conditions of the sentences containing them. This is not a mere choice of convenience. Rather, the structure of these theories has implications for many foundational issues. For one, because of the role of semantic theorizing within the larger context of theories of language, a semantic theory characterizes what sort of activity language use basically is, in a sense of "basically" I will explain shortly $(\S 2)$. Further, the dialectical space surrounding various debates about meaning depends in part on what the right semantic theory turns out to be.

To substantiate and illustrate both of these claims, I'll focus on the semantic theory Robert Brandom sketches in his Making it Explicit [Brandom, 1994], making reference along the way to developments in Between Saying and Doing [Brandom, 2008]. I'll argue that it is best viewed as a special kind of dynamic semantics, pioneered by Heim [1982], Kamp [2002]. ${ }^{1}$ Because of its distinctive reliance on norms, I'll call Brandom's version normative dynamics (§4). One upshot of embracing this normative dynamics consists in a reshaping of the debate about the normativity of meaning $(\S 5)$.

I'll end with some critical remarks about both the viability of the semantic theory and its motivations ( $\S 6)$. I'll argue that Brandom's definition of entailment is unworkable, that the close tie between semantics and epistemology implicit in his reliance on norms has extremely counter-intuitive consequences, and finally, that one of the main arguments in favor of the theory, the argument from anaphora, fails.

\section{Semantics and Language Use}

There are various ways to mark out the subject matter of semantics. I want to distinguish three. The first goes via the notion of truth: semantics investigates the truth-conditions of sentences and the contribution a subsentential expression makes to the truth-conditions of sentences in which it appears. ${ }^{2}$ Another begins with a hypothesis about how the semantic value of, say, a sentence, is determined. On this usage, semantics concerns the domain of narrowly linguistic and unbendable rules, pragmatics everything else. Semantic values are arrived at by applying these rules to the linguistic objects whose semantic values we're trying to determine. Usually, it is part of this conception of semantics

\footnotetext{
${ }^{1}$ In addition to these early texts, some of the core expositions are provided by Chierchia [1995], Groenendijk and Stokhof [1991], Kamp and Reyle [1993], Veltman [1996].

${ }^{2}$ This seems to be the dominant usage in some of the debates about how semantics and pragmatics interact. See, e.g., Perry [1998], Stanley [2000], Stanley and Szabo [2000]. It is also endorsed by theorists who take it to be constitutive of the subject matter of semantics that we explain why very often, we are happy to endorse the claim that if $S$ means that $p$, then $S$ is true iff $p$ [as, e.g., Borg, 2004, Larson and Segal, 1995].
} 
that semantic values are arrived at compositionally. ${ }^{3}$ In practice, many of the theorists who delineate semantics via the first way also endorse compositionality, and many of the theorists who focus on compositionality also endorse truth-conditional semantics. The difference concerns not whether either principle is endorsed, but which one is fundamental. This comes out quite clearly in Davidson's Truth and Meaning, for example. He begins by endorsing compositionality as a non-negotiable constraint on semantic theories and then argues that truth-conditional semantics are the way to meet it.

The third and final way to pick out the semantic phenomena focuses on the role of semantics in an overall theory of language and language use. This is the conception of semantics that I will employ here, since it allows us to see debates between theories that assign different semantic values to sentences as debates about what kind of theory best serves this role in the overall theoretical edifice. It also allows us to treat as a substantive question whether the feature of sentences that is most relevant to explaining their role in communication specifically and language use generally is determined compositionally.

Begin with an observation. We can do very many things with words: we can assert, question, command, promise, imply, insult, cheer, hire, fire, and lots more. For many of these speech acts, the words we use in the course of performing them are important insofar as they determine, in part, which act we performed. Suppose that in fact, I said that the keys are on the counter. Had I used (suitably) different words, I would have said that the keys are in the closet. Using different words still, I might have asked where the keys are, or asked my interlocutor to get them for me. However, the relationship between the words we use and the speech act we perform is complex. Depending on the attendant circumstances, almost any bit of language can be used to perform almost any speech act.

Given that the phenomenon of language use is this complex, one might simply think that a systematic theory of language and language use is impossible. This is certainly the attitude of some anti-formalist philosophers who follow Austin [1975]. ${ }^{4}$ However, one might also hold that though the phenomena themselves are complex and varied, they are the result of an interaction of relatively independent factors, at least some of which are sufficiently simple to be amenable to systematic theorizing. An analogy: imagine throwing a handful of leaves off a tall building. Each leaf will follow a particular course, and there will be just about no generalization about their flight-paths if we just consider them qua detailed flight-paths. We might nonetheless arrive at theoretically tractable generalizations by focusing on the forces that conspire to produce the flight-paths, rather than the flight-paths themselves.

A parallel approach to language takes what speech act is performed to be

\footnotetext{
${ }^{3}$ This is the dominant way of focusing on semantics in the work of Davidson. See, e.g., the seminal papers Davidson [1984a,b]. For further particularly clear statements of this idea, see Higginbotham [1985, 1989], Szabo [2000]. It is also endorsed by those participants to the semantics/pragmatics debate who deny that semantic interpretation yields something truthevaluable, e.g., Bach [1994], Recanati [2002, 2004].

${ }^{4}$ See, e.g., Travis [1985, 2000].
} 
the result of an interaction between the meaning of the linguistic material used and the context in which it is used. The general strategy is to try to explain many speech acts in terms of performing some basic ones in the right kind of context. Insulting might be asserting something in a certain context, and so on. ${ }^{5}$

This strategy will not result in a single basic speech act. We're likely to be left with a number of speech acts that cannot be reduced one to another, such as asking and asserting. Asking a question does not consist in making an assertion in the right kind of context. These mutually irreducible basic speech acts are usually marked by distinctive linguistic forms, such as the use of interrogatives and indicatives, and at this point we can still try to forge explanatory connections by explaining the meaning of one kind of sentence, such as interrogatives, in terms of the meaning of another kind of sentence, such as indicative ones. ${ }^{6}$ In one way or another, one arrives at a basic speech act in which one uses sentences with a basic kind of meaning. For all of the contemporary semantic theories I'll discuss here, that basic speech act is assertion, and the sentence with the basic meaning is the assertoric sentence. ${ }^{7}$ On this way of marking out the domain of semantics, it is an open question what these meanings are. One possibility, though not the only one, is to say that the meaning of a sentence should be identified with a set of truth-conditions, or perhaps with a more complex object that determines a set of truth-conditions, such as a Fregean or a Russellian proposition.

Semantics, so construed, tells us about the basic nature of assertion, and due to the foundational role of assertion, the basic nature of language use. If the best semantic theory assigns representational features to assertorically used sentences, we can fairly say that language use is basically representational. If the best semantic theory is not couched in terms of representation, language use is something else.

Let me introduce a terminological convention. I'll say that the content of a sentence is whatever is assigned to that sentence by a semantic theory. Propositions are, by definition, things that are or determine truth-conditions. Thus, all semantic theories agree that sentences have contents, and it is a substantive claim that contents are propositions. It is a claim that's rejected by dynamic theories, my next topic.

\footnotetext{
${ }^{5}$ This is one of the crucial ideas motivating Lewis' discussion of performatives in Lewis [1983].

${ }^{6} \mathrm{~A}$ standard strategy analyzes the meaning of a question in terms of its possible answers. The basic idea stems from Hamblin [1958, 1973], Karttunen [1977]. For a recent survey, see Groenendijk and Stokhof [1997].

${ }^{7}$ As before, many of the theorists who endorse one of the first two conceptions of semantics I distinguished earlier also endorse this structure of speech acts and semantic theorizing. The point is just that it is a substantive hypothesis that semantics fits into a theory of communication on these views. For a kind of dissent from this substantive hypothesis, see Cappelen and Lepore [2005]. On their view, semantics are truth-conditional and compositional, but the truth-conditional content of sentence is at best distantly, and certainly unsystematically, related to the content a speaker conveys by using that sentence, even when she is using the sentence literally.
} 


\section{Informational Dynamics}

In an idealized conversation, the participants talk to each other in order to exchange information. Bert is looking for his keys, and Alice says "the keys are on the kitchen counter." Bert accepts what Alice just said. Alice's assertion has two important features. It is true or false, as the case may be, and it alters the state of the conversation in a particular way. Before Alice's assertion (and Bert's accepting it), it would have been odd for Bert to ask Alice to get him the keys. For all that Bert knew then, Alice might not have been in a position to fulfill the request. Once the assertion is made, that request becomes reasonable.

That the assertion has these two features - being truth-evaluable and influencing the course of the conversation - is uncontroversial. Moreover, it seems extremely plausible that we can explain why it has one in terms of the other. On one strategy (static semantics), we say that it altered the state of conversation in the way it did because of its representational features. In order to give this kind of explanation, we need a way of talking about the relevant features of a conversation in such a way that we can easily describe the effects of asserting a proposition. One way to do that is to think of (at least one theoretically important aspect of) a conversation in terms of the information available to all of its participants. As the conversation progresses and information is exchanged, information previously available only to some of the speakers becomes available to all, and what speakers can do at any one point in the conversation-e.g., which requests speakers can reasonably make of each other - depends on that commonly available information. We can thus represent any stage of the conversation simply by pointing to the commonly available information, which we may call the common ground. An assertion of a proposition then alters the state of the conversation by adding that proposition to the common ground. This is a way of explaining the conversational effects of an assertion in terms of its representational contents. ${ }^{8}$

Dynamic theories reverse the order of explanation. They take as the basic feature of an assertion its effect on any given conversation, should it be accepted, and then define its representational features, to the extent that it has any, by abstracting it from the change an assertion of that sentence imposes on the conversation. The effect of asserting "the keys are on the kitchen counter" is to alter the information that is common ground when the assertion is accepted. Its representational features, in virtue of which it is correctly classifiable as true or false, just consist of the information added. ${ }^{9}$

\footnotetext{
${ }^{8}$ This way of thinking about conversations, as well as the notion of shared information and the terminology of common ground, is due to Stalnaker. See his [1999a, 1999b, 2002].

${ }^{9}$ Dynamic semantics, just like static varieties, depend on a semantics/pragmatics distinction. In a static framework, the semantic value of a sentence as used on a particular occasion should not be all of the information conveyed by the use of that sentence. If that was the case, we wouldn't be able to arrive at a systematic theory. Likewise, in a dynamic framework, the content of an assertion shouldn't be identified with all of the effects an assertion has on the context. As in the static framework, we focus on some effects and try to explain other effects - such as the addition of information that is usually considered to be implicated rather than asserted - in terms of the interaction between the initial assertion and the context.
} 
For simple examples such as the ones I've used so far, there is a trivial equivalence between the two directions of explanation. Given a representational content for a particular sentence, we can immediately define the effect its accepted assertion has on by simply incrementally adding its content to the common ground. And given the effect on the common ground of asserting it, we can define its representational content in terms of the increment of information added to the common ground by the assertion. The two approaches cease to be intertranslatable when we consider more complex sentences whose effect on the common ground cannot be identified with an incremental increase of information.

Consider a relatively simple language: it has a finite number of individual constants $a, b, c$, and a finite number of one-place predicates $F, G, H$. The atomic sentences of the language are just what you would expect. It also has three sentential operators: $\neg, \wedge$, and $\diamond$, which obey the obvious rules. $\diamond$ is interpreted as an epistemic possibility modal, it might be the case that. Given individual objects as extensions of the constants and sets as extensions of the predicates relative to a world, we can give the following semantic rules.

Informational Dynamics Let $C$ be a context, identified as a set of worlds (intuitively: the set of worlds compatible with what is presupposed in a conversation at a particular stage). Then the semantic value of a sentence $\sigma, \llbracket \sigma \rrbracket$, is the result of updating $C$ with $\sigma$, written $C[\sigma]$.

If $\sigma$ is an atomic sentence of the form $\Phi(\alpha)$, then $C[\sigma]=C \cap\left\{w: \llbracket \alpha \rrbracket \in \llbracket \Phi \rrbracket^{w}\right\}$.

If $\sigma$ is of the form $\neg \tau$, then $C[\sigma]=C / C[\tau]$.

If $\sigma$ is of the form $\tau \wedge \mu$, then $C[\sigma]=C[\tau][\mu]$.

If $\sigma$ is of the form $\diamond \tau$, then $C[\sigma]=\left\{\begin{array}{ll}C & \text { if } C[\tau] \neq \emptyset \\ \emptyset & \text { if } C[\tau]=\emptyset\end{array}\right.$.

In other words, we identify the semantic value of a sentence as a function from contexts to contexts, informally, as a function from contexts prior to the assertion of the sentence to contexts after the assertion and acceptance of the sentence, but without taking account of pragmatic effects such as implicatures. Such a function is an update. For atomic sentences, the update is a simple intersection of the worlds in the context with the worlds in which the subject of the sentence has the property predicated in the sentence. Negation is interpreted by first updating the context with the negated sentence and then removing the so-updated context from the original one. Conjunction is simply a successive update with each of the conjuncts. Since we're not dealing with phenomena of anaphora or presupposition, the dynamic semantics so far are simply translatable to static semantics. ${ }^{10}$ However, the present rule for interpreting epistemic

\footnotetext{
${ }^{10}$ For an introduction to the problems that presupposition raises, see Kadmon [2001]. For a thorough introduction to how presupposition is accounted for in dynamic semantics, see Beaver [2001].
} 
possibility cannot be simply translated into a representational framework, since it performs a test on the whole context. The context passes the test if it contains at least one world that is a $\tau$-world, and the context fails the test otherwise. If the context passes the test, it is returned unchanged. If the context fails, the context crashes. ${ }^{11}$ Informally, the point of saying that it might be the case that $p$ is to ensure that everybody takes it as a live possibility that it is true that $p .{ }^{12}$ I call this semantic theory informational dynamics because the contexts that are updated by assertions are states of information. This will turn out to be the main contrast with Brandom's semantic theory.

\section{Brandom's Normative Dynamics}

Brandom endorses semantics as I introduced them in $\S 2$ : there is a fundamental speech act with a fundamental kind of content. This basic speech act is assertion, or as Brandom calls it, "making a claim." All other aspects of language use are ultimately reducible to the basic speech act and/or the basic kind of content.

The fundamental sort of move in the game of giving and asking for reasons is making a claim - producing a performance that is propositionally contentful in that it can be the offering of a reason, and reasons can be demanded for it. Other theoretically important concepts are defined in terms of this one. ${ }^{13}$

That this is really about semantics in my sense comes out in his endorsing a semantics/pragmatics distinction, with assertion playing the role of semantics.

[t]he model [of assertion] is intended to serve as the core of a layered account of linguistic practice. [...] For instance, the model appeals only to semantic inferences, that is, inferences involving what is claimed. Pragmatic inferences such as Gricean implicatures have to do rather with the antecedents and consequents of the performance of claiming it. These pragmatic practices form a shell around the more basic semantic ones, which they presuppose. ${ }^{14}$

What, then, is content? In the first passage, Brandom says that assertions are "propositionally" contentful, which suggests that he takes content to be representational. However, other aspects of Brandom's view militate against taking "proposition" in his terminology to mean "representational content." Rather, "propositional" serves to contrast a kind of content that can be used in the course of making an assertion with the contents that can be used in such

\footnotetext{
${ }^{11}$ In general, the important formal result that determines whether a dynamic system can be translated into a static system is contained in van Bentham [1986]. The issue turns on whether all updates can be defined in terms of a certain set of basic operations.

${ }^{12} \mathrm{I}$ put this theory forward for illustrative purposes only, not to suggest that it is the true theory of epistemic modals.

${ }^{13}$ Brandom [1994, 141].

${ }^{14}$ Brandom [1994, 158-9], emphasis in the original.
} 
acts as referring to an object or picking out a property - it thus lines up with the less committal notion of content I introduced in $\S 2$. Support for this reading comes from how Brandom characterizes assertions.

Speech acts, paradigmatically assertions, alter the deontic score, they change what commitments and entitlements it is appropriate to attribute, not only to the one producing the speech act, but also to those to whom it is addressed. ${ }^{15}$

Even more explicitly drawing the connection to the dynamics of conversation:

The significance of an assertion of $p$ can be thought of as a mapping that associates with one social deontic score-characterizing the stage before the speech act is performed, according to some scorekeeper - the set of scores for the conversational stage that results from the assertion, according to the same scorekeeper. ${ }^{16}$

Two points in these quotations deserve emphasis. First, Brandom embraces a dynamic paradigm in that he says that the significance of an assertion "can be thought of as a mapping" from scores to scores. Second, he gives voice to a distinctive conception of what is updated by an assertion: a deontic score. In the first instance, the deontic score is a representation or model of the reasons available to the agents for both action and belief. Brandom makes the further suggestion that we should think of the deontic score in terms of two technical notions he introduces, commitments and entitlements.

We can restrict our focus to commitments, since the updating of the context he proposes goes in stages, beginning with commitments. ${ }^{17}$ We can characterize commitments thus: a speaker is committed to a sentence iff she ought to defend it when challenged. Following Brandom, I'll model the set of commitments as a set of sentences, intuitively, the set of sentences that everyone is committed to. ${ }^{18}$

We now have a sharp contrast with informational dynamics. It conceives of the context as an information state modelled as a set of worlds, and inclusion in the context signifies presupposition. Brandom's dynamics conceives of the context as a set of reasons, modelled as a set of sentences, and inclusion in the context signifies commitment. Because of its emphasis on normative over representational notions, I call it normative dynamics. It is time to explore its implications.

\section{Meaning and Norms}

Like all actions, our linguistic performances are subject to normative critique. "You shouldn't have said that" is a perfectly reasonable thing to say in some

\footnotetext{
${ }^{15}$ Brandom [1994, 142].

${ }^{16}$ Brandom [1994, 190].

${ }^{17}$ See Brandom [1994, 190-1].

${ }^{18}$ I'll discuss how to formulate updates in more detail in the $\S 6.1$, below.
} 
situations. Normativism holds that some of the norms that govern a linguistic performance have their source in the meaning of the linguistic material used. ${ }^{19}$ In doing so, it makes a stronger claim than merely that the meaning of a sentence is relevant to determining the normative status of a speaker using that sentence. The latter claim is uncontroversial, since we sometimes critique agents for not speaking truly, and the meaning of a sentence used is relevant to determining whether the speaker did that.

Normativism also differs from the view that assertion is governed by constitutive norms. On that view, a speaker who makes an assertion is subject to certain norms, simply in virtue of performing an assertion. The relevant norm might be one of knowledge, reasonable belief, or truth. ${ }^{20}$ On any of these specific proposals, there is a distinctively linguistic source for norms governing a speaker's assertions, to wit, the nature of assertion. However, on these views it is crucially not the meaning of the sentence asserted that is the source of the norms. Normativism about meaning is the latter claim.

There is significant debate about how precisely to state the normativist thesis. It concerns how to make the vague formulation that "norms have their source in meaning" more precise. What generalization holds between the meaning of a sentence, the use of that sentence, and the norms a speaker is subject to ${ }^{21}$ But for our purposes, it will suffice to remain with the informal characterization of normativism in terms of sources. Brandom endorses normativism, as well.

Semantics must answer to pragmatics. The theoretical point of attributing semantic content to intentional states, attitudes, and performances is to determine the pragmatic significance of their occurrence in various contexts. This means settling how linguistic expressions of those contents are properly or correctly used, under what circumstances it is appropriate to acquire states and attitudes with those contents, and how one then ought to or is obliged to go on to behave. $^{22}$

\subsection{Objections to Normativism}

Normativism has seen severe critique recently. ${ }^{23}$ In light of this criticism, some of the debate has shifted to investigating whether there is an internal connection not between linguistic meaning and norms but rather between mental content

\footnotetext{
${ }^{19}$ Normativism entered the recent debate with Kripke [1982]. It is a position with many adherents, including Baker and Hacker [1984], Bloor [1997], Boghossian [1989], Glock [1994, 1996], Lance and O'Leary Hawthorne [1998], McDowell [1984], McGinn [1984], Millar [2004], Miller [1998], Pettit [1990], Wright [1980, 1984].

${ }^{20}$ For the knowledge rule, see Williamson [1996]. For a version and defense of the truth-rule, see Weiner [2005]. For a version of the reasonable-belief rule, see Lackey [2007].

${ }^{21} \mathrm{Cf}$. Glüer and Wilkforss [2009b, §2.1.1].

${ }^{22}$ Brandom [1994, 83].

${ }^{23}$ See, e.g., Dretske [2000], Glüer and Pagin [1999], Glüer and Wilkforss [2009a], Hattiangadi [2006], Horwich [1995], Papineau [1999], Wilkforss [2001].
} 
and norms. ${ }^{24}$ In this discussion, I do not want to consider normativism about mental content. My focus is exclusively on normativism about linguistic meaning.

Many of the anti-normativist arguments operate by offering counterexamples, counterexamples that fall into two broad categories, depending on whether they cite cases in which there is a violation of some norm or not. The first is due to, inter alia, Boghossian [2005], who suggests that on an occasion where I want to lie or mislead my audience, I am not violating any norms associated specifically with the meaning of the sentence. ${ }^{25}$ To be sure, I am still open to normative critique, for I am doing something wrong when I deliberately lie or mislead. But, the objection continues, the norms I am violating are epistemic, prudential, or moral norms, not semantic. I take this kind of objection to be inconclusive because it seems to rely on a direct intuition about the source of norms that are being violated, and I am doubtful of the reliability of such intuitions. ${ }^{26}$

A much stronger sort of counterexample focuses on cases where a sentence is used in a way that is literally false but normatively completely acceptable. Because there is no violation of any norms, these counterexamples do not require the same fine-grained intuition about sources of norms.

These counterexamples focus on speakers who aren't seriously asserting the literal content of a sentence, perhaps because they are telling a joke or using the sentence hyperbolically, ironically, or sarcastically. Such speakers can use a sentence without being open to any kind of rational criticism, even if the sentence is literally false. Consider Grice's famous example of a speaker who, informed of the perfidy of someone she considered a friend, says he is a fine friend. ${ }^{27}$ In a situation in which the audience is completely clear on the kind of speech act being performed, it is of course possible to point out that the literal content is false - he's no friend at all, as it turns out. But there doesn't seem to be anything normatively wrong with the speaker's performance. ${ }^{28}$

\footnotetext{
${ }^{24}$ See Boghossian [2003], Gibbard [2003], Wedgwood [2002, 2007]. Indeed, Boghossian [2003] rejects his earlier defense of normativism.

${ }^{25}$ Hattiangadi [2006] argues in a similar vein.

${ }^{26} \mathrm{I}$ am doubtful of these intuitions for parallel reasons as I am doubtful of intuitions about how to draw the distinction between semantics and pragmatics, or for that matter, what the basic concept of semantic theorizing should be. Whether a sentence is felicitous or odd in a context is the result of the interaction of many different factors, and while the result of their interaction is open to inspection by intuition-perhaps better: by direct judgment- the individual factors are not. Investigating them requires the use of theoretically motivated tools. Likewise, I think that the overall normative status of an action is open to direct judgment. How that status comes about is not. For a more direct response to Boghossian's and Hattiangadi, see also Whiting [2007].

${ }^{27}$ See Grice [1991]. For each of the examples in the text, one may challenge that the false proposition really is the meaning of the sentence at issue, in this case, that the literal meaning is really that he is a good friend. Especially in the case of metaphors, it has been argued that the metaphorical meaning of a metaphorically used sentence really is the literal meaning. for the purposes of this discussion, I will simply grant the opponent of normativism that there are examples of the sort she posits, and I'll use he's a fine friend to illustrate the strategy I am offering the proponent of normativism.

${ }^{28}$ Given this kind of objection, we can see why proponents of normativist views consider
} 
The normativist thus faces a challenge. She needs to explain how there can be some norms that apply to speech acts in which a sentence is used, where the norms have their source in the meaning of that sentence, and which nonetheless fail to apply in some cases in which the sentence is used with its ordinary meaning.

\subsection{A Dynamic Response}

Because dynamic semantics blend force and content in a way that truth-conditional semantics do not, they face a structurally similar challenge with respect to sentences embedded in unasserted environments. Dynamic theories have solved this problem, and I want to model a response on behalf of the normativist on that solution.

One might have thought that a dynamic semantic theory is committed to analyzing an assertion of a sentence of the form it is not the case that $p$ as, inter alia, an assertion of $p$, since that sentence occurs with its ordinary meaning, and the meaning of that sentence just is a context-update, the formal counterpart of an assertion. Dynamic semantic theories might thus be thought to predict that a speaker who asserts it is not the case that $p$ asserts both a sentence and its negation, thereby contradicting herself.

Dynamic theories avoid this problem by being sophisticated about the relationship between the assertoric force that is part of the meaning of a complex sentence and the assertoric force that is part of the meaning of its component sentences. Consider again the rule for interpreting negation.

\section{Informational Dynamics (excerpt)}

$$
\text { If } \sigma \text { is of the form } \neg \tau \text {, then } C[\sigma]=C / C[\tau] \text {. }
$$

The update imposed on a context by the assertion of a negation is defined in terms of an update with the negated sentence. However, the total update does not include as its proper part an update with the negated sentence (we're not excluding all of the $\neg p$-worlds from the final context). Instead, dynamic semantics introduce what is usually called a "local context," a context that is the result of updating with a component of the sentence and which in turn can be used to define further updates. In this case, we begin with a context, update it with the negated sentence, rather than the whole negation, and subtract the result from our starting context.

On behalf of the normativist, I want to draw a very close parallel between unasserted linguistic environments - e.g., negation - and non-serious assertoric uses of sentences - e.g., irony. In both cases, the meaning of the sentence includes an assertion-like update of the context, and in both cases, the assertionlike update of the context is such that the ultimate effect of the speech act does

mental content a more promising subject. It doesn't seem as if there is a kind of non-serious belief that could serve as a counterexample in the way that non-serious uses of sentences do here. 
not include the actual assertion of the sentence. In the case of irony, for example, the speaker uses the sentence ironically and the audience reasons about what an update of the context with that sentence would amount to. Speaker and audience then update the context with a different claim, roughly that the perfidious "friend" is no friend at all. ${ }^{29}$ Crucially, the norms associated with the content of the sentence (the update) only apply to the speaker if the update percolates up and is a proper part of the update the speaker as a whole proposes.

I want to draw explicit attention to one feature of this defense of normativism. One might think that the appeal to a dynamic semantic theory is idle, that all I am suggesting on behalf of the normativist is an embrace of the content-force distinction. But that would miss a crucial component of the response. To see this, consider how a similar appeal to that distinction would look in the context of a static theory. To say that whether certain norms apply to a speaker using a sentence is determined by the (presence or absence) of a certain force is just to say that the source of norms is to the force with which that sentence is used. But on a static conception of meaning, the force is no part of the content. At best, then, an appeal to the content-force distinction in a static theory can be used to defend assertion as a source of norms, not meaning. It is precisely because in dynamic theories, force and content are both aspects of semantic content that this is a defense of the normativism.

\subsection{From Normative Dynamics to Normativism}

This is not the only benefit that reorienting the semantics towards a normative dynamic conception can bring. It also allows us to give a new positive argument for the normativity thesis.

A speaker who uses a sentence assertorically is proposing an update of the context. Given that contexts in the normative dynamic framework consist of commitments, a speaker who proposes an update of the context is thereby incurring a commitment with distinctive normative requirements. That is to say, because updates are defined in terms of commitments, whatever normative demands a speaker is under when she incurs a new commitment, she is also under in proposing an update of a context.

In this argument, the normative conception of the context in terms of commitments is crucial. We can see this by considering an attempt at a parallel argument using an informational conception of the context. There, too, a speaker who asserts a sentence proposes an update of the context. But all we know about the context, as far as the semantics tells us, is that it is an information state, and the proposed update adds information to that state. But then we cannot conclude that a speaker has to satisfy any normative demands. In the ordinary course of events, speakers naturally need to have some kind of standing (such as expertise, justification for the belief that the information added is

\footnotetext{
${ }^{29}$ This is essentially the Gricean idea of saying something false to convey something true, transposed into the dynamic semantic setting.
} 
correct, etc.), but that may just be because in the ordinary course of events, speakers engage in conversations in order to achieve aims that impose the relevant normative requirements. From the point of view of the semantics, that use of language is purely contingent.

Let me end this section with two remarks. First, all of the work of the argument happens "off stage" in the characterization of the context in terms of commitments. Once this is granted, normativism follows immediately. The normative dynamic semantics is thus a very powerful philosophical position. Second, many of the proponents of normativism don't just think that it is true, they also think that it is obviously so, part of our simple, pre-theoretic conception of meaning. They emphasize this dialectical status because they want to go on to use it as a constraint on theories of meaning. Most famously, Kripke [1982] uses normativism this way in arguing against dispositionalism, the view that a speaker's dispositions to use a term in a certain way could fix the meaning of that term. The argument that I've provided for normativism on Brandom's behalf cannot play this dialectical role. A normative dynamic theory is not pretheoretically obvious, whatever else one may wish to say about it.

\section{Objections}

I now turn to the critical parts of my discussion. I'll discuss one of the crucial notions required to formulate proper updates, that of entailment; the connection between semantics and epistemology implicit in construing contexts in terms of commitments; and finally, the argument from anaphora, which is supposed to help establish the normative dynamics.

\subsection{Entailment}

If we model a context as a set of sentences (intuitively: the set of sentences that everyone in the conversation is committed to at a given stage in that conversation), and an update as an addition of a commitment, i.e., an addition of a sentence, we need a theory of how that addition alters the overall set of commitments. We need to say, for example, whether the additional commitment makes for an incoherent set of sentences. This, in turn, requires us to have a theory of entailment, since the addition of a commitment can generate an incoherence by entailing something that is incompatible with what's already in the context, or with something that's entailed by what's already in the context. "Kim is in the room" isn't just incompatible with "Kim isn't in the room," but also with "Nobody is in the room." Notice, though, that even the first incoherence doesn't come for free for Brandom, since we need a semantics for the logical operators that delivers, for example, that one cannot be committed to both $p$ and $\neg p .^{30}$ In the case of truth-conditional semantics, the truth-

\footnotetext{
${ }^{30}$ Usually, the demand for semantics for the operators is put by saying that we want to be able to interpret complex sentences in terms of their parts, i.e., compositionally. However, Brandom denies that languages work compositionally. That's why I use the less committal
} 
tables tell us how to interpret these connectives. In a dynamic paradigm, we have to instead show how this recursive interpretation can take place without appeal to truth-conditional semantics. In informational dynamics, we define the update imposed by a complex sentence in terms of the update imposed by its components. But this is not a trivial task. We can get a feel for the difficulty by contrasting conjunction and negation. Conjunction is easy: a speaker who asserts a conjunction $p \wedge q$ and thus commits herself to it just commits herself to each of the conjuncts $p$ and $q$. Negation is trickier: committing oneself to $\neg p$ is not the same as not committing oneself to $p$-the latter, but not the former, is compatible with agnosticism about $p$.

\subsubsection{Definitions of Entailment and Negation}

In his [1994], Brandom does not offer a semantic theory for logical operators. ${ }^{31}$ He does provide one, based within its framework, in Brandom [2008]. The semantics for negation piggyback on the definition of entailment, so I'll take these two in turn. Brandom's core idea is to take as basic the notion of incompatibility: two sentences are incompatible just in case commitment to one precludes commitment to the other. This is red all over is incompatible with this is green all over in this sense. ${ }^{32}$ In fact, we need a slightly more general notion, that of two sets of sentences being incompatible with each other. That's because a sentence can be incompatible with a set of sentences, even though it's compatible with each of the members of that set. Vide $\neg q$ and $\{p, p \rightarrow q\}$.

Given such an incompatibility relation, defined over the cartesian product of the powerset of the language with itself, Brandom defines entailment as follows.

Incompatibility Entailment $S_{1}$ entails $S_{2}$ iff everything incompatible with $S_{2}$ is also incompatible with $S_{1}$.

The easiest way to see how this works is by considering how it mimics the more familiar possible worlds definition of entailment in terms of containment of sets of worlds: $S_{1}$ entails $S_{2}$ iff the set of $S_{1}$-worlds is a subset of the set of $S_{2}$-worlds.

Begin with the $S_{2}$-worlds. Now consider all of the sets of worlds that are wholly disjoint from the set of $S_{2}$-worlds - the set of propositions incompatible with $S_{2}$. These together are the complement of the $S_{2}$-worlds. Now, suppose that it's also true that the set of $S_{1}$ worlds is wholly disjoint from this large set, the complement of the $S_{2}$-worlds. In that case, the set of $S_{1}$-worlds must be wholly contained in the set of $S_{2}$-worlds. That's just Brandom's definition of entailment.

Given this definition of entailment, the definition of negation is almost immediate. We essentially want to mimic taking the complement of a set of worlds, and we've already seen how to do that. Take all of the sets of worlds that are

\footnotetext{
notion in the text.

${ }^{31}$ A point noted by Lance [2001].

${ }^{32} \mathrm{As}$ Brandom points out, the sense in which commitment to one precludes commitment to the other is normative, not descriptive. Speakers do at times commit themselves to incompatible sentences [see, e.g., Brandom, 2008, 120].
} 
wholly disjoint from the original one and form their union. In Brandom's words: in order to define the interpretation of $\neg S$ in terms of $S$ and incompatibility, take all of the sentences that are incompatible with $S$. The negation of $S$ is defined as the sentence that is entailed by each of them. ${ }^{33}$

\subsubsection{The Problem with Persistence}

A sentence may be incompatible with a set of sentences without being incompatible with each of its subsets. However, Brandom holds that incompatibility persists in the opposite direction: if a set of sentences $X$ is incompatible with a set of sentences $Y$, then any superset of $X$ is also incompatible with $Y$. Call this claim PERSISTENCE. ${ }^{34}$ We can see why Brandom requires this persistence condition. If it failed, we wouldn't be assured that a set of sentences entails each of its subsets. ${ }^{35}$

Unfortunately, PERSISTENCE fails, and with it the definition of entailment, and with that, the semantics for the logical operators, along with the proper formulation of updates. The problem is that Brandom wants incompatibility relations to hold not just between logically inconsistent (sets of) sentences, but also between what he calls materially incompatible sets of sentences, such as \{this is red, this is ripe and $\{$ this is a blackberry\}. This incompatibility holds on the strength of the fact that ripe blackberries are black, not red. ${ }^{36} \mathrm{Cru}-$ cially, if we convert this incompatibility into the corresponding inference, using the first set as premises to infer the negation of the second, we are drawing a non-monotonic inference - one that is good given these premises, but may become bad were we to add premises. And once we allow for non-monotonic inferences, PERSISTENCE crashes systematically and pervasively. For example: \{this is a bird $\}$ is incompatible with $\{$ this doesn't fly\}, but $\{$ this is a bird, this is a penguin $\}$ is compatible with $\{$ this doesn't fly\}.

A natural response for Brandom is to say that the inference from this is a bird

\footnotetext{
${ }^{33}$ Two remarks. Brandom has to mimic the operation of taking the union of all of the incompatibilities with $S$ in terms of entailment, rather than disjunction, since we're trying to define the logical connectives and hence cannot help ourselves to them at the outset.

Second, the equivalence between worlds-talk and Brandom's incompatibility-talk is only a heuristic. It turns on how rich the language is over which we're defining incompatibility and hence entailment, roughly, whether there are sentences to cover all of logical space. To take an example, suppose we have a language that only contains three color-related sentences: this is red, this is blue, this is green. In that case, it's not the case that this is red is equivalent on Brandom's view to this is blue or green, whereas this equivalence obviously doesn't hold on a possible worlds conception. I take it that Brandom considers this a feature, not a bug.

${ }^{34}$ The idea is introduced at Brandom [2008, 123], stated formally at Brandom [2008, 141].

${ }^{35}$ Argument: let there be two sets of sentences $X, Y$, and two sentences $\phi, \psi$ such that

(i) $X$ is incompatible with $\psi$

(ii) $X \cup\{\phi\}$ is compatible with $\psi$

By the assumption that Persistence fails, we are assured that there are suitable $X, Y, \phi, \psi$. By the definition of entailment, $X \cup\{\phi\} \models X$ iff every set of sentences incompatible with $X$ is also incompatible with $X \cup\{\phi\}$. But by assumption, $\psi$ is incompatible with $X$ but compatible with $X \cup\{\phi\}$. Hence, $X \cup\{\phi\} \not \models X$.

${ }^{36}$ This is Brandom's own example [Brandom, 2008, 123].
} 
to this flies is really enthemematic, and once the silent premise is made explicit, the inference is valid, not just a good default inference. ${ }^{37}$ That removes the previous objection, but it comes at the cost of making the semantics of generic generalizations too weak. To develop this objection, I need to say something about how to interpret generics in Brandom's framework. On his view, generics such as birds fly and blackberries are black when they're ripe aren't claims in quite the same way as simple sentences about particular matters of fact. Rather, they represent inferential commitments or rules. Hence, commitment to a generic doesn't amount to the same thing as commitment to a sentence about a particular matter of fact. The latter is vindicated by adducing evidence that the world is the relevant way. The former is vindicated just in case the corresponding inference is a good one. I'll say that if and only if that is the case, commitment to the generic is vindicated in that language.

On the original view, for example, a language in which the inference from this is a bird to this flies is a good one ipso facto vindicates commitment to birds fly. This strategy for interpreting generics has the great benefit of accounting for a basic fact about them: a language cannot simultaneously vindicate commitment to a generic and its negation. Thus, it's a logical fact about generics that birds fly and birds don't fly can't both be vindicated. But the revised view I am considering on Brandom's behalf can no longer maintain this fact.

On the revised model, commitment to birds fly is vindicated in a language iff the inference from $\{$ this is a bird, $\theta\}$ to this flies is valid, where $\theta$ is whatever is needed to make the inference valid. Heuristically, we can think of $\theta$ as saying that this is a normal bird. But now birds fly and birds don't fly are compatible. Commitment to birds don't fly is vindicated in a language iff the inference from \{this is a bird, $\chi$ \} to this doesn't fly is valid. But both of these inferences may well be valid. Considering the pervasiveness of generics in language, this is a serious problem.

\subsection{Closure and Entailment}

The concerns about the logical operators I have just raised do not directly attack Brandom's normative conception of context. They turn on the relationship between the semantics of the logical operators and the non-monotonicity of default inference. My next objection targets the normativity more directly by challenging the possibility of defining entailment correlatively with the inheritance of commitment, understood as a distinctively epistemic (and thus normative) notion.

Recall that the two basic notions that are taken as primitively understood are commitment and incompatibility. They are connected via the principle that two sentences are incompatible iff commitment to one precludes commitment to the other. Once entailment is defined in terms of incompatibility along the lines

\footnotetext{
${ }^{37} \mathrm{NB}$ : If Brandom avails himself of this strategy, much of his motivation for positing materially good inference has to go by the boards, since the strategy I'm pursuing on his behalf in the text runs counter to his concerns about the "dogma of formalism" [see Brandom, 1994, 97ff].
} 
sketched in the previous section, entailment too is connected to commitment. The relevant principle is: one sentence entails another iff commitment to the first makes commitment to the other obligatory. It is this principle I now wish to challenge. The basic concern is that the epistemic notion of commitment, and the further epistemic notion of commitment inheritance, is more fragile than our intuitive notion of entailment.

Consider a case of transmission failure, one in which knowledge is not closed under entailment, not even known entailment. As a concrete example, consider

(Z) This is a zebra.

$(\neg \mathrm{M})$ This is not a cleverly disguised mule.

(KZ) I know that this is a zebra.

$(\mathrm{K} \neg \mathrm{M})$ I know that this is not a cleverly disguised mule.

Intuitively, (Z) entails $(\neg \mathrm{M})$, but (KZ) does not entail $(\mathrm{K} \neg \mathrm{M})$. The latter fact shows us that commitment to $(\mathrm{Z})$ does not make obligatory commitment to $(\neg \mathrm{M})$. Given that $(\mathrm{KZ})$ does not entail $(\mathrm{K} \neg \mathrm{M})$, it's possible for an agent to not vindicate commitment to $(\neg \mathrm{M})$, i.e., for $(\mathrm{K} \neg \mathrm{M})$ to be false and yet for her to vindicate commitment to $(\mathrm{Z})$, i.e., for $(\mathrm{KZ})$ to be true. By the connection between commitment and entitlement, it follows that $(Z)$ does not entail $(\neg \mathrm{M})$.

How might the proponents of Brandom's link between commitment and entailment respond? Can they model the strategy that semanticists can use who have a grip on the entailment between $(\mathrm{Z})$ and $(\neg \mathrm{M})$ that isn't mediated by the connection between commitments to these sentences? These semanticists can say that the standards of evidence required to verify a knowledge ascription change as we move from consideration of $(\mathrm{KZ})$ to $(\mathrm{K} \neg \mathrm{M}) .{ }^{38}$ At least in principle, the proponents of Brandom's position could give a similar description of the situation.

They want to explain why it is that someone could be epistemically without fault if they commit themselves to $(\mathrm{Z})$, have enough evidence to vindicate that commitment, but if the question arises as to whether they can vindicate commitment to $(\neg \mathrm{M})$, their evidence is insufficient to answer affirmatively. And they would like to give this explanation while taking for granted that commitment to $(\mathrm{Z})$ makes commitment to $(\neg \mathrm{M})$ obligatory, so that they can maintain their link between entailment and commitment inheritance at the same time as accepting that $(\mathrm{Z})$ really does entail $(\neg \mathrm{M})$.

Here's the strategy. They accept that commitment to (Z) makes commitment to $(\neg \mathrm{M})$ obligatory. And they say that, so long as we don't actually challenge $(\neg \mathrm{M})$, justification sufficient to vindicate (Z) is also sufficient to vindicate $(\neg \mathrm{M})$. However, as soon as we actually challenge $(\neg \mathrm{M})$, the requirements for vindicating commitment to it rise. This gives the appearance that commitment to $(\mathrm{Z})$

\footnotetext{
${ }^{38}$ Theories disagree over the semantic/pragmatic mechanisms that induce this change, and they also differ over how to think about standards of evidence. That debate is irrelevant to present concerns.
} 
does not make commitment to $(\neg \mathrm{M})$ obligatory, but only because as soon as we look at the commitment to $(\neg \mathrm{M})$ "explicitly," the standards for vindication shift. So commitment to $(\mathrm{Z})$ does bring with it commitment to $(\neg \mathrm{M})$, but only at the lower requirement for vindication.

I have two concerns about this response. First, it's not clear how a proponent of Brandom's position could argue for one way of describing the situation over the other. What reason could we have for saying that commitment to $(\mathrm{Z})$ makes commitment to $(\neg \mathrm{M})$ obligatory, it's just that we can't see it? Notice that the phenomenon of raised standards is completely systematic. Whenever we move from a challenge to $(\mathrm{Z})$ to a challenge to $(\neg \mathrm{M})$, we automatically raise the requirements for vindication. That means that one natural response is unavailable. If it turned out that the raising of requirements was something that happened now and again, but not always, it might be possible to argue on grounds of theoretical economy that we should accept that commitment is always inherited. But since the requirements always rise, this avenue of response is cut off.

The second concern is tied more directly to Brandom's theory. On Brandom's view, notions like commitment are connected very tightly to use. To be committed to a sentence is thus closely tied to having to give a defense of that claim. But presumably, to be committed to giving a defense of that claim requires being able to defend the claim when challenged. And this connection between commitment and defense when challenged is incompatible with the description I've just offered Brandom's proponent. For this conception doesn't really make sense of being committed to a sentence, and being able to vindicate that commitment, while at the same time not being able to vindicate that commitment when challenged.

\subsection{The Argument from Anaphora}

The argument from anaphora roughly holds that some phenomena connected to anaphora are such that we can accommodate them only if we adopt a normative dynamic theory. ${ }^{39}$ The argument in outline is that sentences containing expressions like proper names and demonstratives can figure in reasoning, and that their role in reasoning can only be explained within a normative dynamic theory.

Consider the following two arguments.

\footnotetext{
${ }^{39}$ Brandom [1997] highlights an alternative argumentative strategy that focuses on anaphora-like phenomena via what he calls the prosentential theory of truth, building on work by Grover [1992], Grover et al. [1975].
} 
(A-i) Jane is tall.

(A-ii) She is young.

$\therefore$ (A-iii) Somebody is young and tall.

(D-i) [Pointing AT Jane] She is tall.

(D-ii) [Pointing AT JANE] She is young.

$\therefore$ (D-iii) Somebody is young and tall.

Informally speaking, in the A-argument reference is established only once. The reference of she as it appears in the second premise piggybacks on that of Jane. In this case, she is used anaphorically, with Jane as the antecedent. By contrast, in the $\mathrm{D}$-argument, reference is established separately twice over, and she is used as a demonstrative or deictically.

Brandom suggests that the difference between separately established reference and piggybacking reference is epistemically important. It's possible for a speaker to know that the premises of the D-argument are true, to understand them, and yet not to be justified in accepting the conclusion of the argument because there is a notion of understanding the premises and knowing them to be true that is compatible with not knowing that the two occurrences of she corefer. Hence, the argument might trade on an equivocation. ${ }^{40}$ Intuitively, no such possibility exists for the A-argument, since the reference of she is just anaphorically determined to be the same as Jane. I propose to grant Brandom that there is such a distinction.

He goes on to argue that, on a truth-conditional semantic theory, we in fact cannot make sense of the idea that the interpretation of she in (A-ii) is tied to the interpretation of Jane in (A-i). A static semantic theory ends up treating the A-argument exactly on a par with the D-argument. This is Brandom's argument from anaphora.

The key issue for the proponent of a static theory is to not beg the question against Brandom. For that reason, she cannot simply say that the pronoun is interpreted anaphorically as we can see, for example, by consulting the logical form of the sentences and noting that she and Jane are coindexed. The force of Brandom's question is what co-indexing in those cases in which it's a matter of coreference amounts to. At the same time, we should keep the scope of Brandom's concern clearly in view. He is presumably not concerned with with variable binding uses of pronouns, as in every boy loves his $_{1}$ mother, since the pronoun doesn't refer at all.

Brandom considers the following answer.

One idea would be to assimilate the relation between an anaphoric dependent and its antecedent to the relation between a demonstrative and what is demonstrated. Anaphoric dependents would be

${ }^{40}$ Cf. Brandom [1994, 462]. 
understood as indexical tokenings that referred to their antecedents. In a tokening / Hegel understood Kant's argument, but he did not refute it $/ i$, the token $/$ it $/ i$ would be understood as meaning what a token /that/ would mean, if it could be arranged that what was demonstrated was the antecedent tokening / Kant's argument/ $i$.

But as it stands this cannot be how such a story would go. For in that case the tokening /it/ $i$ would be conceived of as intersubstitutable, not with other tokenings co-identified with /Kant's argument/ $i$, but with tokenings that (presystematically) would be said to refer to the tokening /Kant's argument/i - such as / the very tokening of type 〈Kant's argument> that was just uttered (or tagged with the index $i) /$. That is not what Hegel understood but failed to refute, for he never heard of that tokening. ${ }^{41}$

That is, Brandom suggests that coindexing amounts to demonstrating the linguistic material the pronoun is anaphoric on. This is an obvious no-go. The proposal Brandom considers here amounts to saying that she refers to Jane in $(\mathrm{A}-\mathrm{i})$, not the person but the name. And in that case, we don't even have coreference, let alone grammatically ensured coreference.

A slightly more promising option is to interpret the anaphorically used pronoun as meaning roughly: what that [POINTING AT THE ANTECEDENT] refers to. Brandom offers arguments in another part of the book that seek to establish that we cannot make sense of the refers locution independently of his preferred normative dynamics. But in that case, the argument from anaphora adds nothing to the case against static semantics.

In fact, we can give an even stronger reply to Brandom's objection by offering a solution that doesn't appeal to the notion of reference. As Lewis [1983] points out, there are many ways for an object to be salient in such a way as to make it eligible to be the referent of a deictically used expression. One way is for the object to be sufficiently strange that it comes with built-in salience, at least in the context of the conversation - think of a goat walking into a lecture hall. A speaker might also make it salient by pointing. But finally, and this is the important one, a speaker might make it salient by mentioning it. Thus, in the A-argument, the utterance of the first premise makes Jane salient by mentioning her, while the utterance of the second premise exploits that salience to fix the reference of the pronoun. ${ }^{42}$

It is clear that this cannot be the whole account of anaphoric interpretation, since this sketch predicts that it's possible for a pronoun to be anaphoric on a name, no matter what structural relationships might hold between the name and

\footnotetext{
${ }^{41}$ Brandom [1994, 463-4].

${ }^{42}$ As I emphasized in the main text, we are not concerned with variable binding uses of pronouns, either within sentences or across them, as in $A \operatorname{man}_{1}$ came to the door. He $\mathrm{H}_{1}$ was selling encyclopedias. For that reason, the debate about whether the mechanism I describe in the text can be extended to cover cases of cross-sentential anaphora is irrelevant to the viability of my response. Proponents of the view that such an extension is possible include Lewis [1983]. It has been critiqued by Heim [1982].
} 
the pronoun. But we know that there are syntactic constraints on coindexing, so this story would need to be supplemented. It might even turn out that we cannot give a set of constraints that predict exactly the right anaphoric options. Perhaps such an argument can be sustained, and even turned into an argument for a normative dynamics. As it stands, however, Brandom's argument is unconvincing.

These considerations also put Brandom's division of labor in a new light. Specifically about anaphora, he says that

[The account Brandom offers] does not pretend to address the questions about anaphora that linguists and cognitive psychologists have been most concerned with - namely, when it is correct to [...] treat one expression rather than another as the anaphoric antecedent of another, what lexical or syntactic cues there are for adopting this attitude, or how audiences in fact go about deciding which of various possible readings to adopt. The question of interest here is what it is to do the trick - what counts as doing the trick - rather than when it is called for or how it can be brought off. ${ }^{43}$

It's true that semantic theories generally do not offer accounts of anaphoraresolution, i.e., of how speakers decide which of several different grammatically available interpretations is the one at issue in a conversation. However, they $d o$ offer competing accounts of what readings are available - one of the important areas of disagreement in the debate between static and informational dynamic semantics is precisely over that question. The preceding arguments are intended to show that a neat separation between debates about when anaphora is possible and what anaphora is cannot be maintained.

\section{Conclusion}

This paper has been concerned with Brandom's semantic theory, evaluating it as far as possible on its own terms, detached from the broader themes of his philosophy. I've argued that it has important philosophical implications for the debate about normativism. It offers a new defense against objections to normativism as well as a new argument for it. However, I've also suggested that there are significant empirical problems for the theory. Both the concerns about the clash between persistence and non-monotonic inference and about the argument from anaphora illustrate what is at once the boon and burden of language-oriented philosophy: foundational and empirical issues are tightly intertwined.

${ }^{43}$ Brandom [1994, 457], emphasis in the original. 


\section{References}

John L. Austin. How To Do Things With Words. Harvard UP, Cambridge, MA, 1975.

Kent Bach. Conversational implicature. Mind and Language, 9:124-62, 1994.

G. P. Baker and P. M. S. Hacker. Scepticism, Rules and Language. Basil Blackwell, Oxford, 1984.

David I. Beaver. Presupposition and Assertion in Dynamic Semantics. CSLI, Stanford, 2001.

D. Bloor. Wittgenstein, Rules and Institutions. Routledge, London, 1997.

P.A. Boghossian. The normativity of content. Philosophical Issues, 13:31-45, 2003.

Paul A. Boghossian. The rule-following considerations. Mind, 98(392):507-549, 1989.

Paul A. Boghossian. Is meaning normative? In A. Beckerman and C. Nimtz, editors, Philosophy-Science-Scientific Philosophy, pages 205-218. Mentis, Paderborn, 2005.

Emma Borg. Minimal Semantics. Oxford UP, Oxford, 2004.

Robert B. Brandom. Making it Explicit. Harvard UP, Cambridge, MA, 1994.

Robert B. Brandom. From truth to semantics: A path through making it explicit. In Enrique Villanueva, editor, Philosophical Issues, Vol. 8. Truth, pages 141-154. Ridgeview Publishing Company, Ridgeview, 1997.

Robert B. Brandom. Between Saying and Doing. Oxford UP, Oxford, 2008.

Herman Cappelen and Ernie Lepore. Insensitive Semantics. Blackwell Publishing, Malden, MA, 2005.

Gennaro Chierchia. Dynamics of Meaning. University of Chicago Press, Chicago, 1995.

Donald Davidson. Theories of meaning and learnable languages. In Inquiries into Truth 83 Interpretation, pages 3-15. Oxford UP, New York, 1984a.

Donald Davidson. Truth and meaning. In Inquiries into Truth $\mathscr{E}$ Interpretation, pages 17-36. Oxford UP, New York, 1984b.

Fred Dretske. Norms, history, and the constitution of the mental. In Perception, Knowledge, and Belief. Selected Essays, pages 242-258. Cambridge UP, Cambridge, UK, 2000.

Allan Gibbard. Thoughts and norms. Philosophical Issues, 13:83-98, 2003. 
H-J Glock. Wittgenstein vs. quine on logical necessity. In S. Tegharian, editor, Wittgenstein and Contemporary Philosophy, pages 185-222. Thoemmes, Bristol, 1994.

H-J Glock. Necessity and normativity. In H. Sluga and D. G. Stern, editors, The Cambridge Companion to Wittgenstein, pages 198-225. Cambridge UP, Cambridge, UK, 1996.

Kathrin Glüer and Peter Pagin. Rules of meaning and practical reasoning. Synthese, 117(2):207-227, 1999.

Kathrin Glüer and Åsa Wilkforss. Against content normativity. Mind, 118(469): 31-70, 2009a.

Kathrin Glüer and Åsa Wilkforss. The normativity of meaning and content. In Edward N. Zalta, editor, The Stanford Encyclopedia of Philosophy. Summer 2009 edition, 2009b.

H.P. Grice. Logic and conversation. In Studies in the Ways of Words, pages 22-40. Harvard UP, Cambridge, 1991.

Jeroen Groenendijk and Martin Stokhof. Questions. In Johan van Bentham and Alice ter Meulen, editors, Handbook of Logic and Language, pages 1055-1124. Elsevier and MIT Press, Amsterdam, 1997.

Joroen Groenendijk and Martin Stokhof. Dynamic predicate logic. Linguistics and Philosophy, 14(1):39-100, 1991.

Dorothy L. Grover. A Prosentential Theory of Truth. Princeton UP, Princeton, 1992.

Dorothy L. Grover, Jr. Camp, Joseph L., and Jr. Belnap, Nuel D. A prosentential theory of truth. Philosophical Studies, 27(2):73-125, 1975.

C. L. Hamblin. Questions. Austalasian Journal of Philosophy, 36:159-168, 1958.

C. L. Hamblin. Questions in montague english. Foundations of Language, 10: 41-53, 1973.

Anandi Hattiangadi. Is meaning normative? Mind \& Language, 21(2):220-240, 2006.

Irene Heim. The Semantics of Definite and Indefinite Noun Phrases. PhD thesis, University of Massachusetts, Amherst, 1982.

James Higginbotham. On semantics. Linguistic Inquiry, 16(4):547-593, 1985.

James Higginbotham. Elucidations of meaning. Linguistics and Philosophy, 12 (4):465-517, 1989.

Paul Horwich. Meaning, use, and truth. Mind, 104(414):355-368, 1995. 
Nirit Kadmon. Formal Pragmatics. Blackwell, Malden, MA, 2001.

Hans Kamp. A theory of truth and semantic interpretation. In Paul Portner and Barbara H. Partee, editors, Formal Semantics: The Essential Readings, pages 189-222. Blackwell, Oxford, 2002.

Hans Kamp and Uwe Reyle. From Discourse to Logic. Kluwer, Dordrecht, 1993.

Lauri Karttunen. Syntax and semantics of questions. Linguistics and Philosophy, 1(1):3-44, 1977.

Saul Kripke. Wittgenstein: On Rules and Private Language. Harvard UP, Cambridge, MA, 1982.

Jennifer Lackey. Norms of assertion. Noûs, 41(4):594-626, 2007.

M. N. Lance and J. O'Leary Hawthorne. The Grammar of Meaning: Normativity and Semantic Discourse. Cambridge UP, Cambridge, UK, 1998.

Mark Lance. The logical structure of linguistic commitment iii: Brandomian scorekeeping and incompatibility. Journal of Philosophical Logic, 30(5):439464, 2001.

Richard Larson and Gabriel Segal. Knowledge of Meaning. MIT Press, Cambridge, MA, 1995.

David K. Lewis. Scorekeeping in a language game. In Philosophical Papers, Vol. 1, pages 233-249. Oxford UP, New York, 1983.

John McDowell. Wittgenstein on following a rule. Synthese, 58(3):325-363, 1984.

Colin McGinn. Wittgenstein on Meaning. Basil Blackwell, Oxford, 1984.

A. Millar. Understanding People. Oxford UP, Oxford, 2004.

A. Miller. Philosophy of Language. McGill-Queens University Press, Montreal and Kingston, 1998.

David Papineau. Normativity and judgement. Aristotelian Society Supplementary Volume, 73:17-43, 1999.

John Perry. Indexicals, contexts, and unarticulated constituents. In Proceedings of the 1995 CSLI-Amsterdam Logic, Language and Computation Conference. CSLI Publications, Stanford, 1998.

P. Pettit. The reality of rule-following. Mind, 99(393):1-21, 1990.

François Recanati. Unarticulated constituents. Linguistics and Philosophy, 25: 299-345, 2002.

François Recanati. Literal Meaning. Cambridge UP, Cambridge, UK, 2004. 
Robert C. Stalnaker. Assertion. In Context and Content, pages 78-95. Oxford UP, Oxford, 1999a.

Robert C. Stalnaker. Pragmatic presupposition. In Context and Content, pages 47-62. Oxford UP, Oxford, 1999b.

Robert C. Stalnaker. Common ground. Linguistics and Philosophy, 25(5-6): 701-721, 2002.

Jason C. Stanley. Context and logical form. Linguistics and Philosophy, 23(4): 319-434, 2000.

Jason C. Stanley and Zoltan Gendler Szabo. On quantifier domain restriction. Mind and Language, 15(2-3):219-261, 2000.

Zoltan Gendler Szabo. Descriptions and uniqueness. Philosophical Studies, 101 (1):29-57, 2000.

Charles Travis. On what is strictly speaking true. Canadian Journal of Philosophy, 15(2):187-229, 1985.

Charles Travis. Unshadowed Thought. Harvard UP, Cambridge, MA, 2000.

J. van Bentham. Essays in Logical Semantics. D. Reidel Publishing Company, Dordrecht, 1986.

Frank Veltman. Defaults in update semantics. Journal of Philosophical Logic, 25(3):221-261, 1996.

Ralph Wedgwood. The aim of belief. Philosophical Perspectives, 16:276-297, 2002.

Ralph Wedgwood. The Nature of Normativity. Oxford UP, Oxford, 2007.

Matthew Weiner. Must we know what we say? The Philosophical Review, 114 (2):227-251, 2005 .

Daniel Whiting. The normativity of meaning defended. Analysis, 67(2):133-140, 2007.

Åsa Wilkforss. Semantic normativity. Philosophical Studies, 102(2):203-226, 2001.

Timothy Williamson. Knowing and asserting. The Philosophical Review, 105 (4):489-523, 1996.

C. Wright. Wittgenstein on the Foundations of Mathematics. Duckworth, London, 1980.

C. Wright. Kripke's account of the argument against private language. Journal of Philosophy, 81(12):759-777, 1984. 